\title{
An Experimental Study on Performance Characteristics of a Hydrogen Fuelled Spark Ignition Engine
}

\author{
Sung Bin Han \\ Department of Mechanical \& Automotive Engineering, Induk University \\ (Received 3 March 2014, Revised 19 March 2014, Accepted 20 March 2014) \\ Abstract
}

\begin{abstract}
The purpose of this study is to obtain low-emission and high-efficiency in LPG engine with hydrogen enrichment. The objective of this paper is to clarify the effects of hydrogen enrichment in LPG fuelled engine on exhaust emission, thermal efficiency and performance. The compression ratio of 8 was selected to avoid abnormal combustion. To maintain equal heating value of fuel blend, the amount of LPG was decreased as hydrogen was gradually added. The relative air-fuel ratio was increased from 0.76 to 1.5 , and the ignition timing was controlled to be at minimum spark advance for best torque (MBT).
\end{abstract}

Key words : Spark Ignition Engine, Engine performance, Thermal efficiency, Emissions, Relative air-fuel ratio

\section{INTRODUCTION}

In recent years, given the dramatically increasing number of cars, public concern has steadily increased regarding a possible shortage of fossil fuel resources, energy safety policies, and environmental pollution regulations. In particular, the environmental problems and growing energy crises associated with global warming and energy preservation have enhanced the focus on alternative fuel research and the fuel efficiency of the internal combustion engine (Yoon and Lee, 2011; Yoon et al., 2008).

Fossil fuels such as petroleum, natural gas and coal meet most of the world's energy demand, at present time. But combustion products of these fossil fuels, such as carbon monoxide (CO), carbon dioxide $\left(\mathrm{CO}_{2}\right)$, oxides of sulfur $\left(\mathrm{SO}_{\mathrm{x}}\right)$, oxides of

\footnotetext{
${ }^{\dagger}$ To whom corresponding should be addressed.

Department of Mechanical \& Automotive Engineering, Induk University, 12 Choansan-ro, Nowon-gu, Seoul 139-749, Korea. Tel : 02-950-7545 E-mail : sungbinhan@induk.ac.kr
}

nitrogen $\left(\mathrm{NO}_{\mathrm{x}}\right)$, hydrocarbon ( $\left.\mathrm{HC}\right)$, toxic metals, and ashes have been causing many environmental problems and posing great danger for the world. It is very well known that the solution to these problems is to replace the existing fossil fuel systems with the clean renewable energy ones, even though this could impose some design modifications. Therefore, alternative fuel research becomes the main purpose nowadays (Kahraman, 2007).

Hydrogen, as an energy source, has some distinct benefits for its high efficiency, convenience in storage, transportation, and conversion. Hydrogen has much wider flammable limit than methane, propane or gasoline and the minimum ignition energy is about an order of magnitude lower than for other combustibles (Ma, et al., 2003; Kumar and Ramesh, 2003 ).

Because of its excellent ignitability and high adiabatic flame temperature of hydrogen fuel, the ignition delay period, flame development duration, rapid burning duration and overall burning angle are 
remarkably shorter than those in gasoline and diesel engine (Cracknell et al., 2002).

From an environmental point of view there is an increasing interest among the supplier's to investigate LPG as a transportation fuel. It was found that the liquid petroleum gas, roughly a mixture of propane and butane, gives a benefit in terms of toxic hydrocarbons emissions and ozone formation due to its composition and $\mathrm{CO}_{2}$ emission levels(Heffel,2003).

Comparing the properties of hydrogen and LPG, it is possible to obtain interesting fuel economy and emission reductions. However, today the concept of hydrogen enriched LPG fuel, as fuel for internal combustion engines, has a greater interest than pure hydrogen powered engines because it involves fewer modification to the engines and their fueling systems. In fact, hydrogen and gasoline can be burned together in a wide range of air-fuel ratio, providing such good performances, as high thermal efficiency and reduced pollutant emissions (Lee et al., 2002).

Many researchers studied the effect of the addition of hydrogen into natural gas on performances and emissions in the past several years. They found that an increase in the amount of premixed hydrogen could stabilize the combustion process and reduced hydrocarbon $(\mathrm{HC})$ and $\mathrm{CO}$ emissions but increase the $\mathrm{NO}_{\mathrm{x}}$ emissions in a methane stratified charge spark ignition engine with hydrogen premixing under the same excess air ratio operation (Liu et al., 2008; Choi et al., 2005).

Currently, diesel engines are broadly used in transportation vehicles due to their low carbon-dioxide emissions and excellent fuel consumption characteristics. Diesel engines using compression ignition have a superior thermal efficiency and engine torque, compared to gasoline engines. However, even for diesel engines, the current stringent exhaust emission regulations are a significant obstacle. In order to meet these regulations, many research groups have suggested high-tech combustion strategies such as premixed combustion, low-temperature combustion, dual-fuel combustion, and multiple-injection strategies. In addition, alternative fuels such as biodiesel, bioethanol, gas-to-liquid (GTL), dimethyl-ether (DME), and liquefied petroleum gas (LPG) are being actively investigated for their potential to reduce exhaust emissions from the internal combustion engine (Park et al., 2012).

For the past several years, the author has been interested in retrofitting old engines, for example, a compression ignition engine that is over 7 years old or a diesel vehicle with over $150,000 \mathrm{~km}$. This research is an experimental investigation of the effects of the fuel supply method, namely Mixer and LPi methods, on engine performance and emissions characteristics. These experiments, in which an old compression ignition engine is converted into a spark ignition engine, should contribute to a definite reduction in automotive emissions. For reducing the exhaust emissions of an old compression ignition engine, the author is trying to use LPG instead of diesel fuel. In order to achieve this, the current diesel automobile's high compression ratio must be lowered and LPG must be supplied as the fuel. This leads to the question of how exhaust and other performance characteristics will vary depending on how the fuel is supplied.

The purpose of this study is to obtain low-emission and high-efficiency in LPG engine with hydrogen enrichment. The objective of this paper is to clarify the effects of hydrogen enrichment in LPG fuelled engine on exhaust emission, thermal efficiency and performance. The compression ratio of 8 was selected to avoid abnormal combustion.

\section{EXPERIMENTAL APPARATUS AND PROCEDURE}

Figure 1 shows the schematic diagram of the experimental apparatus. In order to determine the ideal compression ratio, the experimental engine 


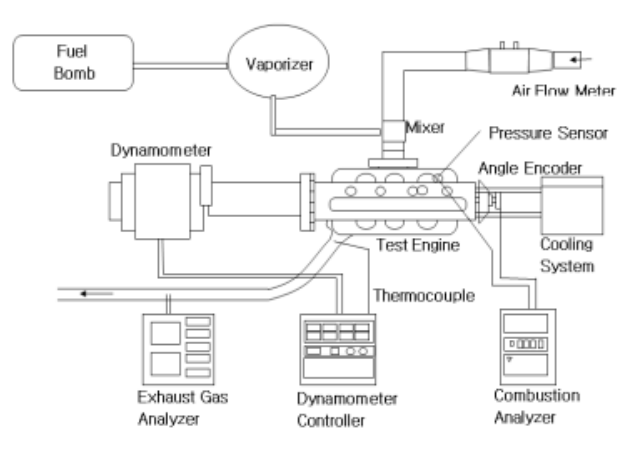

Fig. 1. Schematic diagram of experimental apparatus.

was developed. The variable compression ratio single cylinder engine used in this experiment was a single cylinder spark ignition that had been modified from a 6 cylinder 12 liter diesel engine into engine. Major steps in the engine's fabrication are outlined below, and the specifications are listed in Table 1.

The cylinder head was altered so that a spark plug could be inserted in the place of the injection nozzle, and the piston was modified into a bath tub type. In order to take advantage of the squish effect that occurs at the end of the compression process and subsequently optimize the mixture formation, a bath tub type piston was made. New crankshaft and crankcase were developed. A new flywheel was made so that the desired RPM could be obtained. A balance shaft and a flywheel were made to minimize vibration and acceleration, and the cooling and lubrication system were placed externally in order to more precisely determine engine performance.

The experimental conditions for this study are listed in Table 2. All experiments were conducted at 1400rpm, minimum spark advance for best torque (MBT), wide open throttle (WOT) and a compression ratio of 8 . The compression ratio of 8 was selected to minimize abnormal combustion. To maintain equal heating value, the amount of LPG was decreased, and hydrogen was gradually added.

In a similar manner, the relative air-fuel ratio was increased from 0.8 to 1.3 in increments of 0.1 , and
Table 1. Specification of test engine.

\begin{tabular}{l|l}
\hline Engine type & OHV \\
\hline Number of cylinder & 1 \\
\hline Bore & $130 \mathrm{~mm}$ \\
\hline Stroke & $140 \mathrm{~mm}$ \\
\hline Displacement & $1,858.2 \mathrm{cc}$ \\
\hline Compression ratio & 8 \\
\hline Intake valve open & 18 BTDC \\
\hline Intake valve close & 50 ABDC \\
\hline Exhaust valve open & 50 BBDC \\
\hline Exhaust valve close & 18 ATDC \\
\hline Length of connecting rod & $260 \mathrm{~mm}$ \\
\hline
\end{tabular}

Table 2. Experimental Conditions

\begin{tabular}{c|ll}
\hline \multirow{2}{*}{ Test fuels } & $100 \%$ LPG, & \\
\cline { 2 - 3 } & $90 \%$ LPG $+10 \%$ & hydrogen, \\
\cline { 2 - 3 } & $80 \%$ LPG $+20 \%$ & hydrogen \\
\hline $\begin{array}{c}\text { Relative air-fuel } \\
\text { ratio }(\lambda)\end{array}$ & Around $0.8-1.5$ & \\
\hline $\begin{array}{c}\text { Engine speed } \\
(\mathrm{rpm})\end{array}$ & 1400 & \\
\hline $\begin{array}{c}\text { Engine load } \\
\text { condition }\end{array}$ & Wide open throttle & \\
\hline Ignition timing & MBT timing \\
\hline
\end{tabular}

Table 3. Properties of test fuels.

\begin{tabular}{l|c|c}
\hline & $\mathrm{C}_{4} \mathrm{H}_{10}$ & $\mathrm{H}_{2}$ \\
\hline \hline $\begin{array}{l}\text { Low heating value, } \\
\mathrm{MJ} / \mathrm{kg}\end{array}$ & 45.84 & 120 \\
\hline $\begin{array}{l}\text { Theoretical air-fuel } \\
\text { ratio }\end{array}$ & 15.5 & 34.3 \\
\hline Flammability limits & 0.4 to 1.7 & 0.12 to 10.12 \\
\hline Density, kg/m ${ }^{3}$ & 2.64 & 0.0899 \\
\hline $\begin{array}{l}\text { Adiabatic flame } \\
\text { temperature, } \mathrm{K}\end{array}$ & 2263 & 2657 \\
\hline $\begin{array}{l}\text { Auto ignition } \\
\text { temperature, } \mathrm{K}\end{array}$ & 858 & 723 \\
\hline $\begin{array}{l}\text { Turbulent burning } \\
\text { velocity, } \mathrm{m} / \mathrm{s}\end{array}$ & 0.4 & 1.7 \\
\hline
\end{tabular}

the ignition timing was controlled to be at MBT each time.

The properties of test fuels, LPG and hydrogen are listed in Table 3.

Figure 2 shows the fuel supply system. A desired mixture of LPG and hydrogen was used as the fuel system, and the fuel rate was controlled with a duty 


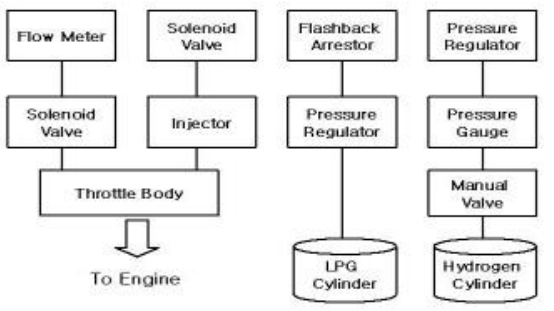

Fig. 2. Fuel supply system

drive and a solenoid valve. LPG consumption was measured via a balance scale with a degree of precision of $1 \mathrm{~g}$. High purity hydrogen at $200 \mathrm{bar}$ was flown through the pressure controller, the mass flow meter, the solenoid valve, and the flame arrestor on its way to the intake. If the relative air-fuel ratio and the LPG consumption rate do not reach target values, the duty and main jet are controlled accordingly. A surge tank was installed on the inlet side to minimize the experimental engine's intake pulsation, and an external pump was used for the coolant and the oil in order to minimize power loss.

Experimental parameters are dependent of the relative air-fuel ratio and hydrogen supplement rate. The hydrogen supplement rate is defined as follows:

Hydrogen supplement rate $(\%)=$

$$
\frac{m_{H 2} \times Q_{L(H 2)}}{m_{C 4 H 10} \times Q_{L(C 4 H 10)}+m_{H 2} \times Q_{L(H 2)}}
$$

where $\mathrm{mH}_{2}$ is the mass flow rate of hydrogen, $\mathrm{mC}_{4} \mathrm{H}_{10}$ the mass flow rate of $\mathrm{LPG}, \mathrm{QL}\left(\mathrm{H}_{2}\right)$ the lower heating value of hydrogen, and $\mathrm{QL}\left(\mathrm{C}_{4} \mathrm{H}_{10}\right)$ the lower heating value of LPG. The $10 \%$ hydrogen supplement rate per heating value is equal to $55 \%$ hydrogen per total fuel volume and $20 \%$ hydrogen supplement rate per heating value is equal to $85 \%$ hydrogen per total fuel volume. The fuel supply system provides LPG/hydrogen mixtures based on same heating value.

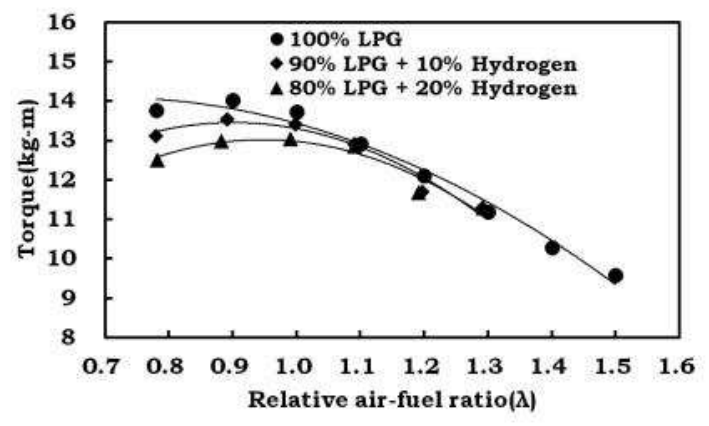

Fig. 3. Engine torque versus relative air-fuel ratio for hydrogen rates.

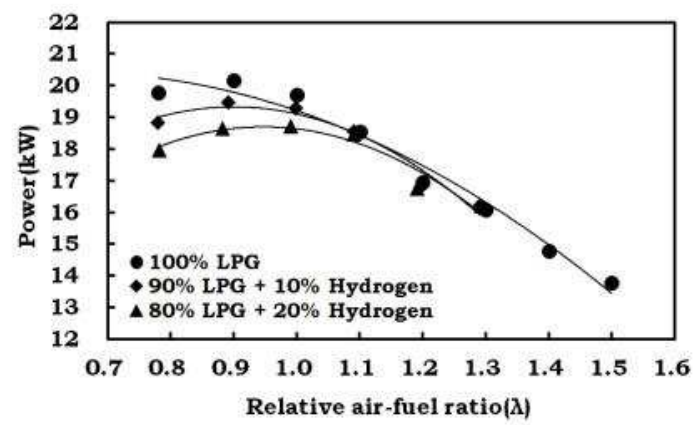

Fig. 4. Brake power versus relative air-fuel ratio for hydrogen rates.

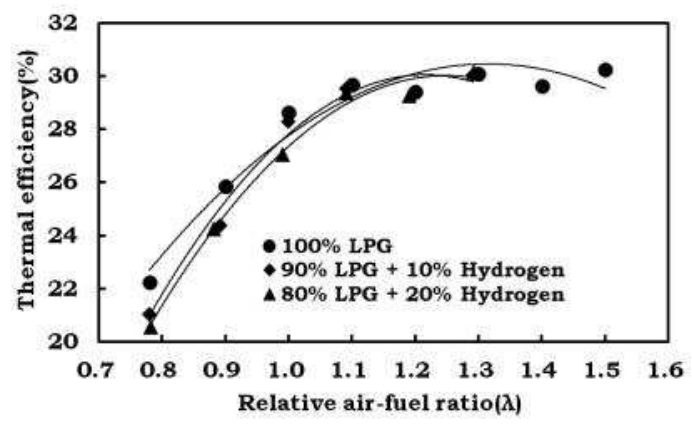

Fig. 5. Brake thermal efficiency versus relative air-fuel ratio for hydrogen rates.

\section{Results and discussion}

The combustion characteristics of fuel-air mixtures and the properties of combustion products, which govern engine performance and efficiency, correlate best for a wide range of fuels relative to the stoichiometric mixture proportions. Where appropriate, therefore, the equivalence ratio was used as the defining parameter.

Figures 3-6 show brake torque, brake power, brake thermal efficiency and brake specific fuel 
consumption (BSFC) as a function of relative air-fuel ratio $(\lambda=$ (air/fuel)actual/(air/fuel) stoichiometric) with the addition of $0 \%, 10 \%$ and $20 \%$ hydrogen at $1400 \mathrm{rpm}$, and a compression ratio 8. In these figures, the engine test of $100 \% \mathrm{LPG}$ is possible to operate to the extent of $\lambda=1.5$, and the operation limit of relative air-fuel ratio with the addition of $10 \%$ and $20 \%$ hydrogen show around of $\lambda=1.3$.

As shown in Figures 3-5, in general, torque, power and thermal efficiency decrease with the increase of hydrogen supplement rate. The reason for the decreases in torque and power could be that the lack of oxygen increase with the increase of hydrogen supplement rate in the rich mixture zone and result the imperfect combustion. But there is no difference in thermal efficiency in the lean mixture zone. The reason for this result could be that the sufficient oxygen was supplied and hydrogen does much for the fast combustion because hydrogen has four times higher burning velocity.

The torque and power peak slightly rich of stoichiometric, between $\lambda=0.9$ and 1.0. Due to dissociation at the high temperatures following combustion, molecular oxygen is present in the burned gases under stoichiometric conditions, so some additional fuel can be added and partially burned.

This increases the temperature and the number of moles of the burned gases in the cylinder. These effects increase the pressure to give increased torque and power (Park et al., 2012).

Figure 5 shows thermal efficiency as a function of relative air-fuel ratio. As shown in this figure, thermal efficiency decreases with the addition of hydrogen. At $\lambda=1$, thermal efficiency of $100 \%$ LPG shows $28.64 \%$ and thermal efficiency of $80 \%$ LPG shows $27.06 \%$. It means that at $\lambda=1$, thermal efficiency shows a decrease of about $4.8 \%$ with the addition of $20 \%$ hydrogen.

The reason for this increase in thermal efficiency could be that the hydrogen fuel burns all at once.

Figure 6 shows the brake specific fuel consumption (BSFC) as a function of relative air-fuel ratio with the addition of $0 \%, 10 \%$ and $20 \%$ hydrogen at $1400 \mathrm{rpm}$, MBT, and a compression ratio of 8 . BSFC for all test fuels increased as the relative air-fuel ratio increased. And the mass of fuel injection is reduced to correspond with the increase of relative air-fuel ratio. The fact that the BSFC increased as the relative air-fuel ratio increased suggests that the lower power output can be attributed to the reduced injection mass and incomplete combustion in the lean combustion region. And fuel consumption that depends on thermal efficiency is defined as the mass flow rate per hour, and it may depend on the increase of brake power rather than the increase of fuel quantity. The reason for lower fuel consumption with increased hydrogen additions compared to LPG combustion would be the fast flame propagation velocity of hydrogen.

Additionally, LPG fuel ( $0 \%$ hydrogen) has higher BSFC compared to the addition of hydrogen; these higher BSFCs are related to the lower heating value and higher air intake flow rate of the addition of hydrogen. The low heating value (LHV) of LPG fuel is approximately $45.84 \mathrm{MJ} / \mathrm{kg}$, which is approximately $61.8 \%$ lower than that of hydrogen fuel, $120 \mathrm{MJ} / \mathrm{kg}$. Furthermore, LPG fuel increases volumetric efficiency because of its cooling effects and the larger amount of fuel required in the cylinder. The stoichiometric air-fuel ratio for LPG is approximately 15.5 to 1 , while for hydrogen it is approximately 31.3 to 1 . Therefore, more LPG is required to satisfy the stoichiometric ratio compared to hydrogen (Yoon and Lee, 2011).

Figures 7-10 show combustion pressure, pressure-volume $(\mathrm{P}-\mathrm{V})$, heat release and cumulative heat release as a function of crank angle for 250 cycles at $\lambda=1,1400 \mathrm{rpm}$, and MBT (100\% LPG: 14 BTDC; 90\% LPG + 10\% hydrogen: 14 BTDC; $80 \%$ LPG $+20 \%$ hydrogen: 16 BTDC).

As shown in Figure 7, the peak combustion pressure of the addition of $10 \%$ and $20 \%$ hydrogen were lower than that of $100 \%$ LPG. These Figures 


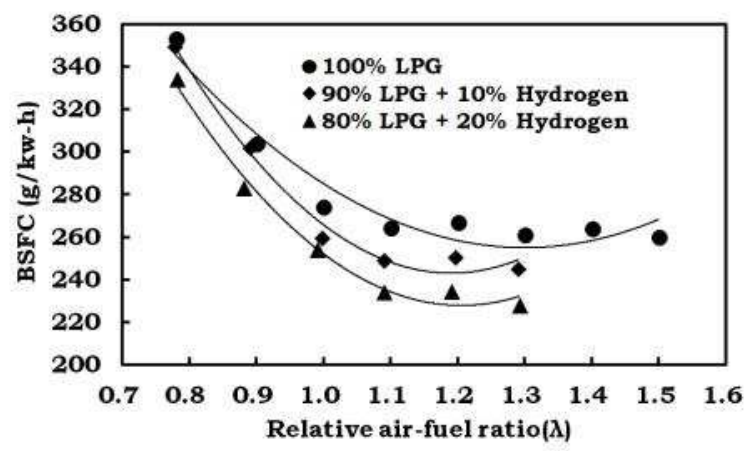

Fig. 6. Brake specific fuel consumption versus relative air-fuel ratio for hydrogen rates.

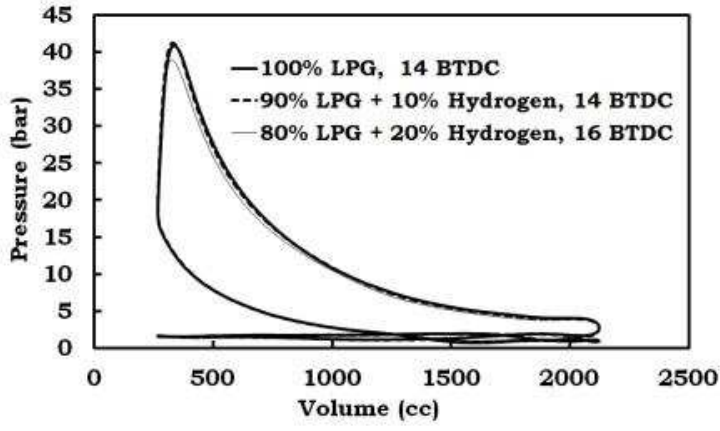

Fig. 8. Pressure-volume diagram according to various hydrogen proportions.

7-10 tend to be similar to Figures $3-5$ at $\lambda=1$.

As shown in Figures 7-10, in general, combustion pressure, heat release and cumulative heat release decrease with the increase of hydrogen supplement rate. The reason for the decreases in torque and power could be that the lack of oxygen increase with the increase of hydrogen supplement rate in the rich mixture zone and result the imperfect combustion. But there is no difference in thermal efficiency in the lean mixture zone. The reason for this result could be that the sufficient oxygen was supplied and hydrogen does much for the fast combustion because hydrogen has four times higher burning velocity as show in Figures 3-5.

As shown in Figure 9, heat release rate was calculated by making a first law analysis of the average pressure versus crank angle variation. For the calculation the contents of the cylinder were assumed to behave as an ideal gas with the specific

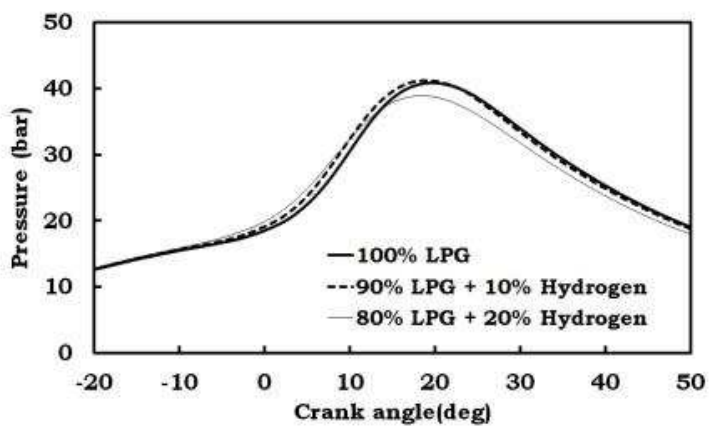

Fig. 7. Cylinder pressure versus crank angle with various hydrogen proportions.

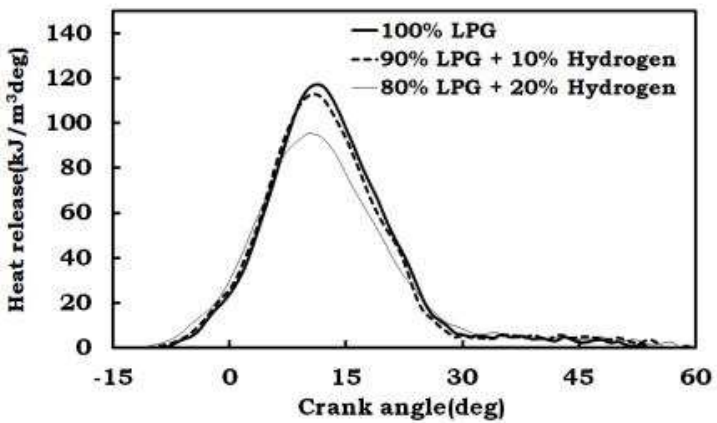

Fig. 9. Heat release versus crank angle with various hydrogen proportions.

heat being dependent on temperature.

The cumulative heat release was then calculated. The start of combustion $\mathrm{w}$ as determined from the rate of pressure rise variation. In general, heat release, cylinder pressure and cumulative heat release decrease with the increase of hydrogen supplement rate, but the ignition timing decreases with the increase of it. From these figures, the fast burning characteristics of hydrogen permit much more satisfactory high-speed engine operation. This would allow an increase in power output with a reduced penalty for lean mixture operation.

Figures 11-13 show $\mathrm{CO}_{2}, \mathrm{CO}$, and $\mathrm{O}_{2}$ emissions as a function of relative air-fuel ratio with the addition of $0 \%, 10 \%$ and $20 \% \quad \mathrm{H}_{2}$. The $\mathrm{CO}$ emissions decrease as the relative air-fuel ratio is increased from 0.76 to 1.3 , and the $\mathrm{CO}$ emissions also decrease as hydrogen is added. For rich relative air-fuel ratios $\lambda=0.78, \mathrm{CO}$ emissions exhibit a maximum value, and it appears that there 


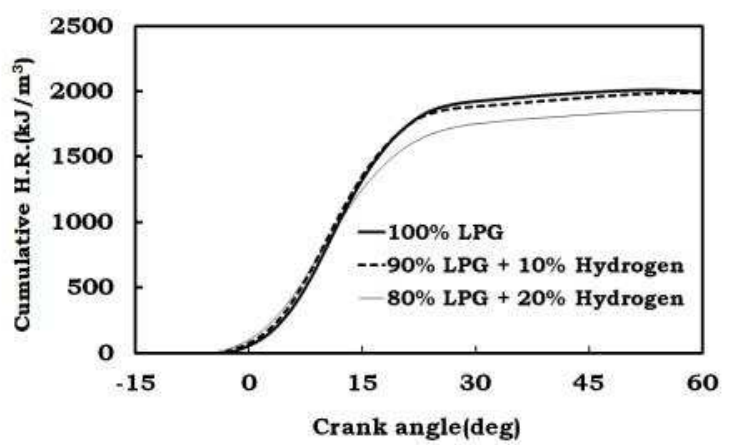

Fig. 10. Cumulative heat release versus crank angle with various hydrogen proportions.

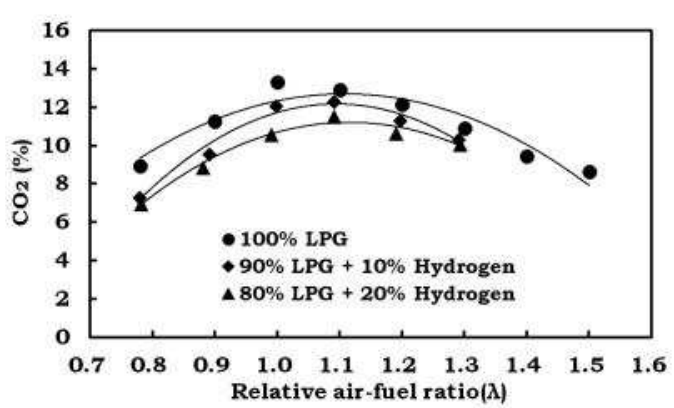

Fig. 11. $\mathrm{CO}_{2}$ emissions versus relative air-fuel ratio for hydrogen rates.

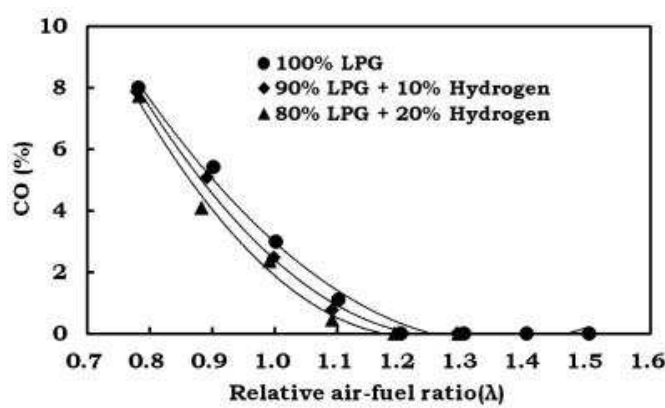

Fig. 12. CO emissions versus relative air-fuel ratio for hydrogen rates.

is almost zero $\mathrm{CO}$ emissions above $\lambda=1.2$. It is expected that hydrogen fuelled engine must have zero $\mathrm{CO}$ emission.

As it is seen in Figure 12, some amount of $\mathrm{CO}$ still present. This is due to the burning of lubricating oil film inside the engine cylinder. As hydrogen is added, $\mathrm{CO}$ emissions tend to diminish. The figure shows that a great quantity of $\mathrm{CO}$ emissions are produced with the rich air-fuel mixture, since an insufficient supply of air prevents

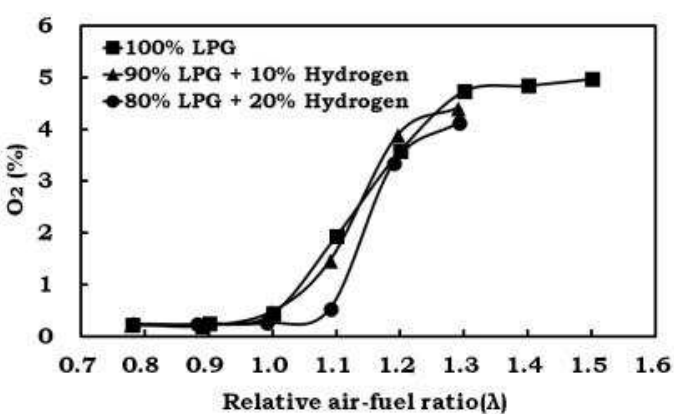

Fig. 13. $\mathrm{O}_{2}$ emissions versus relative air-fuel ratio for hydrogen rates.

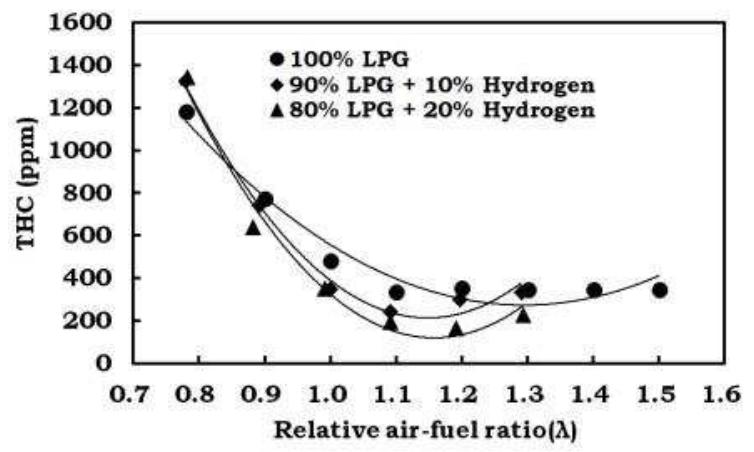

Fig. 14. Total hydrocarbon emissions versus relative air-fuel ratio for hydrogen rates.

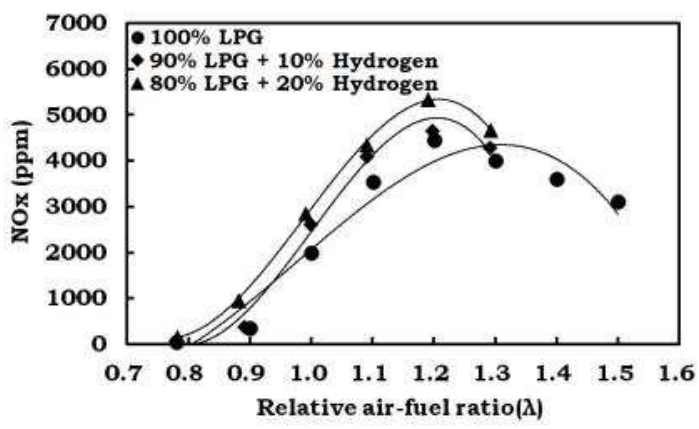

Fig. 15. $\mathrm{NO}_{\mathrm{x}}$ emissions versus relative air-fuel ratio for hydrogen rates.

all carbon of the fuel from becoming the perfect combustion gas $\mathrm{CO}_{2}$. TTherefore, $\mathrm{CO}$ emissions can be represented as a function of the relative air-fuel ratio and might be considerably affected by it. A similar presentation of results for $\mathrm{CO}_{2}$ emissions are seen in Figure 11. Very low $\mathrm{CO}_{2}$ emission values for hydrogen fuelled engine are again due to combustion of the lubricating oil film (Kahraman et al., 2007).

Unburned hydrocarbons from spark ignition 
engine exhaust are a primary component of smog. At present they are attributed to several sources, one of which is the gap between piston and cylinder wall. Unburned charge is pushed into this crevice during the compression stroke. The crevice is narrow enough to quench the flame front, leaving unburned crevice gases, so that during the power stroke, as the piston descends and the exhaust valve opens, these unburned gases re-emerge (Heywood, 1988).

Figure 14 shows THC emissions as a function of relative air-fuel ratio with the addition of $0 \%, 10 \%$ and $20 \% \mathrm{H}_{2}$. THC emissions tend to be similar to $\mathrm{CO}$ emissions at rich relative air-fuel ratio as the ratio is increased from 0.76 to 1.3 , but it is increased at lean side. Also, THC emissions at the rich side decrease with the addition of hydrogen.

Figure 15 shows $\mathrm{NO}_{\mathrm{x}}$ emissions as a function of relative air-fuel ratio with the addition of $0 \%, 10 \%$ and $20 \%$ hydrogen at $1400 \mathrm{rpm}, \mathrm{MBT}$, WOT and a compression ratio of 8 . In general, $\mathrm{NO}_{\mathrm{x}}$ emissions are the maximum at $\lambda=1.2$, and the addition of $20 \%$ hydrogen results in about $20 \%$ increase in the amount of $\mathrm{NO}_{\mathrm{x}}$ emissions compared to that of pure LPG combustion. $\mathrm{NO}_{\mathrm{x}}$ emissions ought to depend on the fast combustion of hydrogen fuel and the higher maximum temperature and pressure in the cylinder compared to LPG combustion. This fact results from the fast combustion of hydrogen fuel and the higher maximum temperature and pressure in the cylinder compared to LPG combustion.

\section{Concluding Remarks}

The results obtained are as follows.

Thermal efficiency decreases with the addition of hydrogen. At $\lambda=1$, thermal efficiency of $100 \%$ LPG shows $28.64 \%$ and thermal efficiency of $80 \%$ LPG shows $27.06 \%$. It means that at $\lambda=1$, thermal efficiency shows a decrease of about $4.8 \%$ with the addition of $20 \%$ hydrogen. The reason for this increase in thermal efficiency could be that the hydrogen fuel burns all at once.
$\mathrm{NO}_{\mathrm{x}}$ emissions are the maximum at about the $\lambda$ $=1.2$, and the addition of $20 \%$ hydrogen results in about $20 \%$ increase in the amount of $\mathrm{NO}_{\mathrm{x}}$ emissions compared to that of pure LPG combustion. This fact results from the fast combustion of hydrogen fuel and the higher maximum temperature and pressure in the cylinder compared to LPG combustion.

$\mathrm{CO}$ emissions decrease if the relative air-fuel ratio is increased from 0.76 to 1.3 , and the $\mathrm{CO}$ emissions also decrease as hydrogen is added. CO emission can be represented as a function of the relative air-fuel ratio.

THC emissions tends to be similar to $\mathrm{CO}$ emissions at rich mixture conditions as the relative air-fuel ratio is increased from 0.76 to 1.3 , but it is increased on the lean side. THC emissions on the rich side also decrease with the addition of hydrogen.

\section{References}

1. Choi, G. H., Chung, Y. J. and Han, S. B. (2005). Performance and emissions characteristics of a hydrogen enriched LPG internal combustion engine at $1400 \mathrm{rpm}$. Int. J. Hydrogen Energy 30, 77-82.

2. Cracknell, R. F., Alcock, J. L., Rowson, J. J., Shirvill, L. C. and Ungut, A. (2002). Safety considerations in retailing hydrogen. SAE Paper 2002-01-1928

3. Heffel, J. W. (2003). $\mathrm{NO}_{\mathrm{x}}$ emissions and performance data for a hydrogen fueled internal combustion engine at 1500 RPM using exhaust gas recirculation. Int. J. Hydrogen Energy 28, 901-908.

4. Heywood, J. B. (1988). Internal Combustion Engine Fundamentals. McGraw-Hill, USA.

5. Kahraman, E., Ozcanli, C. and Ozerdem, B. (2007). An experimental study on performance and emission characteristics of a hydrogen fuelled spark ignition engine. Int. J. Hydrogen Energy 32, 2066-2072. 
6. Kumar, M. S., Ramesh, A. and Nagalingam, B. (2003). Use of hydrogen to enhance the performance of a vegetable oil fuelled compression ignition engine. Int. J. Hydrogen Energy 28, 1143-1154.

7. Lee, K. H., Lee, C. S., Ryu, J. D. and Choi, G. M. (2002). Analysis of combustion and flame propagation characteristics of LPG and gasoline fuels by laser deflection method. KSME Int. J. 16, 935-941.

8. Liu, B., Huang, Z., Zeng, K., Chen, H., Wang, X., Miao, H. and Jiang, D. (2008). Experimental study on emissions of a spark-ignition engine fueled with natural gas-hydrogen blends. Energy Fuels 22, 273-277.

9. Ma J., Su, Y., Zhou, Y. and Zhang, Z. (2003) Simulation and prediction on the performance of a vehicle's hydrogen engine. Int. J. Hydrogen Energy 28, 77-83.

10. Park, S. H., Cha, J. and Lee, C. S. (2012). Reduction of the pollutant emissions from a diesel engine by the application of dimethyl ether (DME) and the control of the intake oxygen flow rate. Energy Fuels 26, 3024-3033.

11. Yoon, S. H. and Lee, C. S. (2011). Lean combustion and emission characteristics of bioethanol and its blends in a spark ignition (SI) engine. Energy Fuels 25, 3484-3492.

12. Yoon, S. H., Park, S. H., Lee, C. S. (2008). Experimental investigation on the fuel properties of biodiesel and its blends at various temperatures. Energy Fuels 22, 652-656. 